
(2017). Justiça social e transformative consumer research: A proposição de uma reflexão teórica. Consumer Behavior Review, 1(Special Edition) 16-31.

ISSN: 2526-7884

Editor: Prof. Dr. Marconi Freitas da Costa Email da revista: cbr@ufpe.br
Avaliação: Double blind review

Recebido: 10 de julho de 2017

Aceito: 26 de setembro de 2017

\title{
JUSTIÇA SOCIAL E TRANSFORMATIVE CONSUMER RESEARCH: A PROPOSIÇÃO DE UMA REFLEXÃO TEÓRICA
}

\author{
Bruno Medeiros Ássimos \\ Marcelo de Rezende Pinto \\ Georgiana Luna Batinga \\ Gustavo Tomaz Almeida
}

Bruno Medeiros Ássimos é Mestre em Administração, Pontifícia Universidade Católica de Minas Gerais - PUC-MG.

Universidade Anhembi Morumbi - UAM, Email: bruno.assimos@gmail.com.

Marcelo de Rezende Pinto é Professor do Programa de Pós-Graduação em

Administração, Pontifícia Universidade Católica de Minas Gerais - PUC-MG. E-mail: marcrez@hotmail.com.

Georgiana Luna Batinga é Doutoranda em Administração, Pontifícia Universidade Católica de Minas Gerais - PUC-MG. E-mail: georgianaluna@yahoo.com.br.

Gustavo Tomaz Almeida é Doutorando em Administração, Pontifícia Universidade Católica de Minas Gerais - PUC-MG. E-mail: gustavo_tomaz_almeida@hotmail.com. Os autores agracedecem aos avaliadores pelos comentários para melhoria do artigo.

\begin{abstract}
Resumo
Quando algo é classificado como socialmente injusto, fica apontado que alguém possui menos do que deveria ter. Este ensaio possui o intuito de provocar uma reflexão inicial sobre as possibilidades de enlace entre a discussão de justiça social e os estudos baseados nas diretrizes da Transformative Consumer Research (TCR), haja vista sua intenção de trazer para os estudos do consumo, públicos e questões de pesquisa historicamente marginalizados, buscando a promoção do bem-estar por meio da mudança social. É preciso que diferentes tipos de interseções que formam um problema sejam investigados para que, de fato, uma discussão aprofundada promova a minimização da injustiça social. Dessa forma, este trabalho aponta que a TCR pode ajudar na promoção da justiça social, dadas as oportunidades que oferece a ampliação de discussões envolvendo o estado e a sociedade civil, principalmente com a adoção de uma abordagem realista crítica de pesquisa.

Palavras-chave: Pesquisa Transformativa do Consumidor, Justiça Social, Realismo Crítico
\end{abstract}




\section{INTRODUÇÃO}

Há muito tempo, pesquisadores do campo do marketing vêm se dedicando às temáticas que vão muito além das questões funcionalistas e preocupações gerenciais. Temáticas diversas ligadas ao campo do macromarketing como marketing social e eticamente responsável (Andrade, Hamza \& Xara-brasil, 2017), bemestar do consumidor (Sirgy, Lee \& Rahtz, 2007), políticas públicas voltadas à segurança alimentar (Oliveira \& Lima-Filho, 2011), combate à pobreza (Peña, Pinheiro, Albuquerque \& Fernandes, 2015), vulnerabilidade social (Janczura, 2012), entre diversos outros, vêm ganhando legitimidade paulatinamente no rol de interesse de congressos e fóruns de discussões da área, sem deixar de mencionar a incorporação desses temas nos diversos periódicos dedicados aos fenômenos de marketing.

No campo do comportamento do consumidor, é possível perceber a emergência do conceito da Transformative Consumer Research - TCR (Ozanne, Pettigrew, Crockett, Firat, Downey, Pescud, 2011). Esse movimento iniciado no âmbito da Association for Consumer Research (ACR) nos Estados Unidos se dedica a ir além da "simples" pesquisado comportamento de consumo de algum grupo social.

A intenção é promover o bem-estar individual e coletivo, ao mesmo tempo em que oferece à sociedade uma resposta positiva aos questionamentos direcionados às ações de marketing (Ozanne et al., 2011; Mick, 2012). Fica implícito que o público-alvo desse tipo de pesquisa está bem focado em grupos vulneráveis como "vítimas" do consumismo, do alcoolismo, de drogas e de outras modalidades de vícios. Faz parte desse rol de possibilidades de pesquisas temáticas envolvendo obesidade, degradação ambiental, pobreza, materialismo, vulnerabilidade de grupos de consumidores, como pessoas com deficiência, analfabetos, crianças, negros, idosos, e outros (Ozanne et al., 2011; Mick, 2012; ACR, 2017).

No Brasil, os estudos envolvendo a TCR são recentes, visto que a maioria deles foram publicados na década de 2010 (tais como Faria e Silva, 2011; Faria e Mota, 2012, Damascena, 2013, Faria e Casotti, 2014; Coelho, 2015; Almeida e Casotti, 2015, Correa, Pinto e Batinga,
2016). A publicação desses trabalhos contribuiu para trazer para o campo do comportamento do consumidor a discussão de questões pouco exploradas.

Deve-se enfatizar que a "essência" e a "potencialidade" da TCR extrapola a compreensão de uma determinada questão do consumo enquanto fenômeno social ao buscar contribuir para a minimização de algum excesso, disfunção ou até mesmo um "desequilíbrio" de forças envolvendo atores no mercado. Ou seja, a proposta da TCR é ir além dos trabalhos tradicionais do campo do consumo no qual a postura do consumidor é passiva e não prevê qualquer tipo de intervenção. Pelo contrário, a intenção é trazer para os estudos do consumo públicos historicamente marginalizados socialmente e, consequentemente, excluídos do "radar" dos pesquisadores com vistas a promover o bemestar dos envolvidos por meio de algum tipo de mudança social.

No contexto das discussões envolvendo a essência da TCR, o conceito de justiça social passa a contar com uma expressiva aderência. A noção do termo "justiça social" ou "justiça distributiva" surgiu em meados dos séculos XIX e XX, quando Grã-Bretanha e Estados Unidos criaram o cenário que permitiu aos cidadãos reivindicarem algum grau de igualdade material (Miller, 1999). Para esse autor, normalmente, o termo é utilizado de maneira associada às concepções de justiça econômica e justiça distributiva, que associado a questões materiais, preocupa-se com a justiça por meio da perspectiva transacional dos mercados globais.

No Brasil, a discussão do tema, pelo menos no campo da Administração, é recente. No entanto, é possível perceber um movimento dos pesquisadores no sentido de abordar questões envolvendo a inclusão de grupos considerados marginais no mercado de trabalho, construção de territórios e espaços públicos que busquem preservar a diversidade social, além das temáticas de ética e desenvolvimento sustentável. Prova dessa ascensão de temas diretamente relacionados à justiça social pode ser constatada por meio da publicação de uma edição do periódico Cadernos EBAPE.BR, no primeiro semestre de 2017, com o título "Pesquisa Científica em Administração e Justiça Social" (Vasconcelos \& Irigaray, 2017). 
Nesse contexto, parecem emergir algumas indagações: quais são os pontos importantes da temática envolvendo a justiça social que fazem sentido para os estudos do consumo? Quais são os pontos marcantes dos estudos transformativos do consumidor que parecem fazer sentido para se promover mudanças positivas na sociedade? Em suma, como seria possível estabelecer conexões entre as discussões de justiça social e os estudos baseados na TCR?

Essas questões culminaram com a iniciativa de se elaborar um ensaio com o intuito de se aprofundar a discussão envolvendo as possibilidades de articulação entre o conceito de justiça social e a implementação de estudos com base na TCR. O objetivo do ensaio, portanto, se adere às discussões advindas da percepção da possibilidade de articulação entre a discussão de justiça social e os estudos de TCR. Um ponto há de se considerado nesse contexto. Não se pretende aqui fechar a discussão, muito menos adotar uma única trilha de entendimento ou discussão. Pelo contrário, a proposta é incitar um debate para que os pesquisadores oriundos de diferentes linhas teóricas e tradições de pesquisa possam expor suas ideias a fim de se construir uma possível "ponte" entre as temáticas, justiça social e estudos transformativos do consumidor.

A elaboração desse ensaio se justifica por alguns motivos. Deve-se ressaltar primeiramente que essa pesquisa contribui para trazer a temática da justiça social para o âmbito dos estudos de marketing, mais precisamente para pesquisas que articulam o bem-estar do consumidor. O campo do comportamento do consumidor carece de abordagens que possam ir além das teorias e técnicas consideradas tradicionais que possam contribuir para o avanço do conhecimento.

A TCR como uma abordagem recente no âmbito dos estudos do comportamento do consumidor parece estar aberta a essas novas interlocuções e possibilidades de articulação. A discussão pode também trazer contribuições para o campo das políticas públicas tanto no que tange àquelas relacionadas às disfunções do consumo como para àquelas concernentes à busca de promoção de justiça social relacionadas ao contexto de diversos públicos vulneráveis.
Para atingir esses objetivos, organizamos o texto em quatro seções, além dessa introdução. A primeira discute a justiça social a partir da visão de diferentes autores. A segunda seção foca esforços no debate sobre questões ligadas à TCR. Incluímos nesse tópico uma discussão que parece fazer todo o sentido quando analisamos a TCR além de seus conceitos fundamentais e aderente à proposta do trabalho: a ontologia e natureza da pesquisa que pode se caracterizar como transformativa. Em seguida, conduzimos comentários sobre os possíveis pontos de contato entre as ideias de justiça social e TCR. Por fim, elaboramos o que chamamos de considerações transitórias com o intuito de fornecer possíveis respostas às várias indagações emergentes do ensaio.

\section{QUESTÕES ENVOLVENDO A JUSTIÇA SOCIAL}

Essa seção tem por objetivo trazer para o debate algumas questões envolvendo o conceito de justiça social. Além de fazer uma revisão geral sobre o termo, buscamos também ao final apontar alguns elementos que possuem aderência aos estudos transformativos do consumidor.

Para Miller (1999), quando se fala sobre a justiça social, está em jogo uma discussão sobre como as coisas boas e más da vida devem ser distribuídas entre os membros de uma sociedade humana. Nesse sentido, quando se classifica alguma política ou algum estado de coisas como socialmente injustas, implicitamente, está sendo apontado que uma pessoa ou um grupo de pessoas goza de menos vantagens do que essa pessoa ou grupo de pessoas devem ter direito, levando em conta o conjunto dos membros da sociedade em questão.

É esse mesmo autor que levanta algumas questões sobre o alcance da justiça social. Em primeiro lugar, quais são exatamente os bens, as vantagens e encargos, cuja alocação é a preocupação da justiça social? Tende-se a pensar imediatamente sobre renda e riqueza, empregos e oportunidades educacionais, mas até onde deve ser estendida a lista e qual o raciocínio para incluir ou excluir itens específicos? Em segundo lugar, se a justiça social tem a ver com a distribuição, o que isso significa exatamente? Deve haver uma agência 
de distribuição que produz os resultados cuja justiça ou injustiça estamos tentando avaliar? E a forma estrita sobre como as políticas governamentais, por exemplo, afetam o nível de renda de diferentes grupos da sociedade, ou nossa preocupação é muito mais ampla do que isso, abrangendo todos os tipos de atividades sociais que determinam a parcela dos bens que as pessoas possuem? Finalmente, o que se entende por uma sociedade humana? Se a justiça social pressupõe que um limite seja estabelecido, como esse limite deve ser corrigido? Todos os seres humanos devem ser incluídos, ou apenas alguns? (Miller, 1999).

Esses apontamentos acabam por demonstrar que o enfrentamento dos aspectos que envolvem a ideia de justiça social não é tarefa trivial, uma vez que estão diretamente atadas às perspectivas que variam de acordo com os valores e os bens dominantes de cada sociedade, assim como são sujeitas às diferentes ideologias atreladas às variadas visões de mundo (Pizzio, 2016).

Nesse contexto, o debate sobre a justiça social baseia-se em uma comunidade ideal imaginada. A desigualdade social é o contraponto da justiça social, que marcada pelo sofrimento absoluto e relativo dos mais pobres, em todos os aspectos da vida, envolve questões mais profundas, como o aspecto histórico (Pogge, 2004). A desigualdade atual é o resultado de décadas e séculos em que sociedades e grupos mais ricos usaram suas vantagens de capital e conhecimento para expandir essas vantagens cada vez mais (Scott, Williams, Baker, Brace-Govan, Downey, Hakstian, Henderson, Loroz and Webb, 2011). Além disso, a falta de conhecimento dos ricos perante as dificuldades dos pobres provoca certa insensibilidade não intencional.

É preciso pensar que os ricos podem ajudar os pobres sem se tornarem pobres e que existe uma ordem formal moldada pelos mais ricos que é imposta aos pobres. Não se trata de propor uma revolução, mas uma ordem alternativa na qual recursos globais são entregues aos pobres como compensação histórica (Pogge, 2004).

Não obstante a complexidade, é preciso salientar alguns pontos que vão permitir o entendimento conceitual da justiça social por Scott et al. (2011). Para esses autores, a justiça social só pode existir em um ambiente no qual determinados elementos estejam presentes, conforme demonstrado a seguir:

Uma população sensibilizada, que entenda que existem direitos básicos a todos os indivíduos. Esta população precisa compreender que existem diferenças sociais fortes, refletindo em relações de poder desiguais, facilmente identificadas em virtude de tons de pele, religião, classe, sexo, etc. 0 malogro em lidar com questões de poder, além da propensão para ver a pobreza simplesmente como resultado de baixa renda, limita profundamente a visão da justiça social;

Um estado forte, dotado de recursos e ferramentas suficientes para garantir sua ação, a estrutura básica. 0 estado precisa possuir a capacidade de manter seu poder coercitivo na forma de leis, impostos, punições e regulamentações (Cohen, 2004);

Uma economia formal, monetizada, monitorada, abrangente, capaz de atuar com o estado em direção ao ideal de justiça social. Ainda que a injustiça esteja marcada por questões de gênero, raça, religião, etc., as propostas podem indicar uma lei que altera rendimentos formais, igualando-os, por exemplo;

Senso de pertencimento. Não é raro encontrar sugestões mais extremas, como a eliminação da religião ou de indivíduos mais abastados. A proposta aqui não é a sua eliminação, mas a percepção de que esses indivíduos e instituições de poder, como a igreja, façam parte da rede de obrigação do ideal de justiça social. Para isso, o senso de pertencimento a uma sociedade, seja ela local, nacional ou global, é um poderoso estimulante para ações altruístas;

Um acordo sobre quais são os bens mínimos para um indivíduo desenvolver seu pleno potencial. Este conjunto de bens precisaria ir além das necessidades biológicas. Contudo, trata-se de um assunto sensível, visto que a definição de qualquer necessidade perpassa por questões relacionadas à história e a cultura.

Scott et al. (2011) propõem que a abertura a soluções criativas indica uma oportunidade para acadêmicos de marketing com uma inclinação social, como os que trabalham sob a égide da TCR. Os autores acreditam que os pesquisadores de marketing estão em ótima posição para avaliar a necessidade de bens para a realização do potencial humano. 
Uma agenda de pesquisa baseada na promoção da justiça social necessita considerar alguns aspectos (Scott et al., 2011):

(1) Subsistência: Ainda que itens evidentes devam compor este ponto, como alimentos, abrigos e roupas, eles só poderão ser identificados sob a manifestação da cultura;

(2) Saúde: A assistência médica varia entre nações, que por meio de suas próprias regulamentações e diretrizes, aprovam procedimentos e medicamentos diferentes;

(3) Segurança: A desigualdade representa maior nível de violência, é preciso verificar o quanto a desigualdade extrema é uma ameaça para a segurança global;

(4) Sociabilidade: Alguns produtos podem ser considerados supérfluos sob determinados olhares, entretanto, eles podem desempenhar uma função social quando permitem a aplicação de códigos de comunicação singular, tornandoos importantes para o potencial humano;

(5) Soberania: A liberdade para desenvolverse deve partir do princípio do livre arbítrio, isso inclui escolhas de consumo;

(6) Espiritualidade: A liberdade de crença parece ser uma parte vital para o bem-estar humano.

Tais práticas envolvem noções de comportamento econômico e governança como parte do desenvolvimento pessoal, tornando-as importantes para a justiça social. Além disso, Scott et al. (2011) apontam três componentes que perpassam por todas as seis áreas apontadas. 0 primeiro deles exige uma revisão do próprio desejo de justiça social, deixando de lado as restrições etnocêntricas e ideológicas inapropriadas e acatando as abordagens mais relevantes para o assunto. 0 segundo ponto consiste na criação de um programa que permita identificar e avaliar as tentativas inovadoras da promoção da justiça social, mesmo que em escala limitada ou baseada em aspectos de mercado. No último ponto, o uso de métodos, teorias, atitudes e áreas de conhecimento diferentes em uma mesma pesquisa são incentivados.

Neste caso, os usuários da pesquisa seriam, principalmente, aqueles com poder de decisão política, ainda que a participação privada não deva ser deixada de lado. Para os autores, a pesquisa deve existir em prol dos oprimidos.
Assim, somente tentando, sem julgamento, elaborar um programa que preserve a dignidade e a identidade, ao alimentar o corpo e educar a mente, a comunidade global pode ir além da pobreza (Scott et al, 2011).

Em uma tentativa de sumarização, Pizzio (2016, p. 358) reitera que "a busca pela superação da desigualdade social tem sido o grande objetivo das teorias contemporâneas de justiça". Sendo assim, a partir das discussões de Nancy Fraser (2006), Pizzio (2016) defende que as reivindicações de justiça social se dividem em dois tipos: um que está relacionado com as reivindicações distributivas, ou seja, uma distribuição mais justa dos recursos e da riqueza; e outro que está mais ligado ao reconhecimento, no qual o objetivo é um mundo que aceite a diferença. Ou seja, pode perceber a existência de dois paradigmas: $0 \quad d a$ redistribuição e o do reconhecimento.

Pizzio (2016) ainda tece comentários acerca das semelhanças e, principalmente, das diferenças dos dois paradigmas. Como semelhança, também a partir das considerações de Fraser (2001), o pesquisador aponta que tanto a redistribuição como o reconhecimento podem se associar aos movimentos sociais concretos, uma vez que a política de redistribuição identifica-se com as políticas de classe, enquanto que a política de reconhecimento se assimila às políticas de identidade e com as lutas de gênero, sexualidade, nacionalidade, raça, entre outros.

No tocante às diferenças, pode-se ressaltar que ambos os paradigmas assumem pontos de vista distintos, propõem diferentes tipos de soluções para as injustiças, divergem em relação às coletividades que sofrem injustiças e, por fim, apresentam ideias distintas acerca das diferenças de grupo.

Vale salientar que alguns trabalhos que almejaram a inserção de algum grau de debate envolvendo a temática da justiça social sob o âmbito do mercado podem ser encontrados em, dentre outros, Gough (2017), que trata do consumo e suas implicações ambientais, buscando a promoção de políticas públicas que amenizem os problemas existentes sem prejudicar as populações mais pobres; Johnson, Thomas and Grier (2017), estudaram os privilégios de mercado e o poder sob a ótica da inclusão de carne halal em uma rede de lanchonetes popular na França. Neste trabalho, 
os autores analisaram como os arranjos de mercado inibem o bem-estar e a igualdade no mercado consumidor; Sridharan, Barringtonand Saunders (2017), tratam da expansão da abordagem de mercado focada em bem-estar, resumido na compreensão das capacidades humanas, em metas de bem-estar e impacto transformador, vislumbrando uma estrutura de mercado boa para os pobres; Loureiro et al. (2016), que propõem a existência de um potencial inexplorado de pesquisa no que se refere a comportamentos morais associados a escolhas de estilo de vida e hábitos, com implicações mais amplas, por exemplo, desperdício, excesso de indulgência, poluição, discriminação, etc.; Hein et al. (2016), debatem a compreensão da natureza complexa, sistêmica, glocalizada, institucionalizada e incorporada das injustiças de gênero e revelam como políticas, mercados e marketing podem perpetuar e resolvê-las; Hamilton et al. (2014), que se concentram nos temas exclusão social, vulnerabilidade, prazer e contentamento, associando-os às representações atuais de pobreza.

Tendo em vista o que foi apresentado até aqui e observando-se a profusão de trabalhos estrangeiros, torna-se essencial deslocar a discussão para o contexto brasileiro. Alguns ajustes no trabalho de Scott et al. (2011) são necessários para que o uso das terminologias como povo, população e cidadão (termos importantes quando se pensa em justiça social) se torne aderente aos conceitos vigentes na legislação brasileira.

Nesse sentido, a Constituição Federal do Brasil (1988) prevê que cidadão é o indivíduo que goza de plenos direitos políticos. Povo é um conjunto de indivíduos que se ligam ao território pelo vínculo da nacionalidade, brasileiros natos ou naturalizados. 0 uso da terminologia população se difere deste último por englobar não só brasileiros natos ou naturalizados, mas estrangeiros e apátridas. Para a apresentação das ideias anteriores acerca do tema justiça social, empregou-se a terminologia população por estar mais próxima a ideologia de igualdade e justiça para todos.

A inserção de um aspecto formal de determinada região ao debate, neste caso, as leis brasileiras, solicita, também, o viés da não formalidade, a cultura. Muitas vezes, o foco de trabalhos que buscam amenizar ou combater a injustiça social perpassa apenas pelo aspecto renda. Contudo, os autores alertam que é preciso abordar os meios sociais de opressão, palco do desenrolar de grande parte da injustiça.

Instituições, mídia e família podem agir na perpetuação da injustiça quando adotam comportamentos e costumes tidos como tradicionais sem nenhum debate crítico, o que muitas vezes pode perpetuar estereótipos propulsores de injustiça (Okin, 1991). Muitos indivíduos de grupos anteriormente invisíveis estão interessados no reconhecimento cultural positivo, ou seja, no fim de estereótipos que minem suas capacidades (Miller, 1999).

Scott et al. (2011) mencionam que uma sociedade busca impulsionar sua cultura, oferecendo resistência e até mesmo proibições a mudanças significativas. Um ponto sensível do debate dos autores é a visão apresentada de que a cultura não deve ir além da necessidade de unir determinado povo, ou seja, ela deve eliminar hábitos antigos que não contribuam para a justiça social e concentrar-se em manter somente o que for necessário para o senso de pertencimento.

Vale salientar ainda que em alguns pontos deste debate, pontos essenciais da TCR foram colocados em relevo como uma possível abordagem a ser utilizada por pesquisadores da área de marketing que desejam trabalhar em prol da justiça social em suas pesquisas. Isso motivou a elaboração do próximo tópico do ensaio que pode ser dividido em dois momentos. 0 primeiro deles consiste na demonstração da TCR em si, ou seja, os princípios fundamentais que guiam a pesquisa sob esta abordagem. Em um segundo momento, o paradigma de pesquisa considerado mais relevante por este trabalho será sugerido ao pesquisador como orientação às pesquisas que se utilizem dos conceitos de justiça social apresentados anteriormente.

\section{A PESQUISA EM TRANSFORMATIVE CONSUMER RESEARCH (TCR)}

Essa seção tem a pretensão de apresentar alguns pontos fundamentais essenciais relacionados à pesquisa em TCR. Esses pontos subsidiarão a discussão exposta no próximo tópico no qual será possível estabelecer as 
possíveis conexões e articulações entre a TCR e o conceito de justiça social.

A TCR nasce do pressuposto de que o ponto de vista do consumidor merece o mesmo respeito que outras perspectivas. Entretanto, não se trata apenas de conhecer os anseios e opiniões daqueles que lançam mão de determinados produtos e serviços, seu objetivo é muito maior, concentrando-se na análise da relação entre o marketing e a sociedade, haja vista que ela não é homogênea (Mari, 2008).

0 termo TCR foi utilizado pela primeira vez para retratar a pesquisa acadêmica voltada a melhoria de vida dos consumidores e do ambiente no qual estão inseridos. Para tal, seus objetos de pesquisa englobam problemas e oportunidades relacionados a esfera do consumo e que, normalmente, recebem pouca atenção dos estudos tradicionais de marketing, dentre os quais: grupos de consumidores vulneráveis como pobres, crianças, adolescentes e analfabetos; problemas sociais como tabaco, álcool e consumo de drogas; nutrição e obesidade; violência em filmes, jogos e outras opções de entretenimento; tomada de decisão financeira e médica; segurança do produto; doação de órgãos e meio ambiente (Mick, 2006).

Dentre os princípios que direcionam os estudos em TCR, é possível citar que a principal finalidade reside na busca da melhoria do bemestar dos consumidores por meio de uma agenda de pesquisa transformadora, desenvolvida por diferentes abordagens paradigmáticas, o que se reflete em uma vasta possibilidade de utilização de técnicas de coletas de dados, teorias e análises.

É nessa possibilidade de articulação teórica que o presente ensaio se insere, até mesmo porque outros trabalhos já cumpriram o papel de apresentar os pontos e conceitos mais importantes da TCR (Coelho, 2015; Pinto, Batinga, Ássimos \& Almeida, 2016). A TCR reconhece que a sociedade possui muitos problemas, ao mesmo tempo sabe que isso significa oportunidades para uma nova era nos estudos de marketing, apontando para si mesma como parte desta mudança e exigindo destemor dos envolvidos no campo de pesquisas do consumidor (Mick, 2012; Crockett et al., 2013).

Outros pontos importantes e que devem ser considerados em pesquisas pautadas pela TCR englobam a visão dos consumidores como parceiros, atuando em regime de colaboração estreita com os pesquisadores, e a divulgação criativa dos resultados, o que compreende a exposição da pesquisa, também, em um linguajar e em meios não acadêmicos (Mick, 2006).

Em síntese, sua caracterização é composta por sua forma dinâmica e evolutiva na condução de pesquisas, assentadas em seis premissas básicas (MICK, 2012): melhorar o bem-estar; funcionar como um grande guarda-chuva que abarca diferentes teorias, métodos, análises e paradigmas, não favorecendo nenhum deles em detrimento de outro, bastando que sejam reconhecidamente relevantes e fortes; focar em contextos socioculturais e situações vividas por consumidores; aproximar consumidores e pesquisadores; e partilhar conhecimentos provenientes da pesquisa para públicos que se beneficiem com seus resultados.

As múltiplas possibilidades de pesquisa em TCR representam variadas possibilidades de reflexão sobre um determinado objeto de estudo. 0 trabalho de Bettany e Burton (2006) traduz as diferentes possibilidades de reflexão que uma pesquisa pode provocar baseando-se nas diferenças de ontologia (singular e múltipla) e natureza da pesquisa (mais controlada ou menos controlada), conforme Figura 1. A ontologia refere-se ao ponto de vista dos pesquisadores, que podem compreender a realidade como externa ao indivíduo ou como produto da consciência do ser. Já a natureza da pesquisa pode entender a realidade social como mais objetivada ou subjetivada (Silveira, 2013), o que se reflete no tipo de reflexão que a pesquisa oferecerá.

A reflexividade objetivista refere-se à prática de enfatizar a explicação das escolhas técnicas, métodos, categorias analíticas, etc. Esta reflexividade pode apresentar problemas de análise de contextos que envolvam aspectos implícitos, como relações de poder e simbolismos. Já a reflexividade perspectiva recebe este nome por considerar as diferentes perspectivas de distintos indivíduos em um encontro de pesquisa, ou então, admite que diferentes grupos terão perspectivas dessemelhantes acerca de diversos tópicos, observando-os por suas próprias lentes.

Esta reflexividade assenta-se no pressuposto de que o objeto de pesquisa é estável e pode ser compreendido de maneiras diferentes. Assim, 
diversas vozes e histórias podem ser representadas. Por sua vez, a reflexividade experiencial relaciona-se a situações de pesquisa nas quais $o$ pesquisador $e \quad o$ pesquisado estão envolvidos em uma partilha de experiências.

A ênfase reside na cocriação de significado por meio de uma investigação íntima. 0 pesquisador considera suas próprias experiências e a de seus entrevistados para compreender o fenômeno estudado. 0 cuidado aqui deve ser pautado pela garantia de que a experiência dos pesquisados não assuma um tom de subordinação perante a experiência do pesquisador.

Por fim, o foco da reflexividade múltipla é a maneira pela qual pesquisador e pesquisados são construídos no decorrer da pesquisa como entidades múltiplas e variáveis da pesquisa. 0 objeto de pesquisa não é tomado como essencial, como na reflexividade experiencial, e não há a busca por experiência compartilhada. A procura aqui é pela formação da essência de uma pesquisa por diversos autores (Bettany \& Burton, 2006).

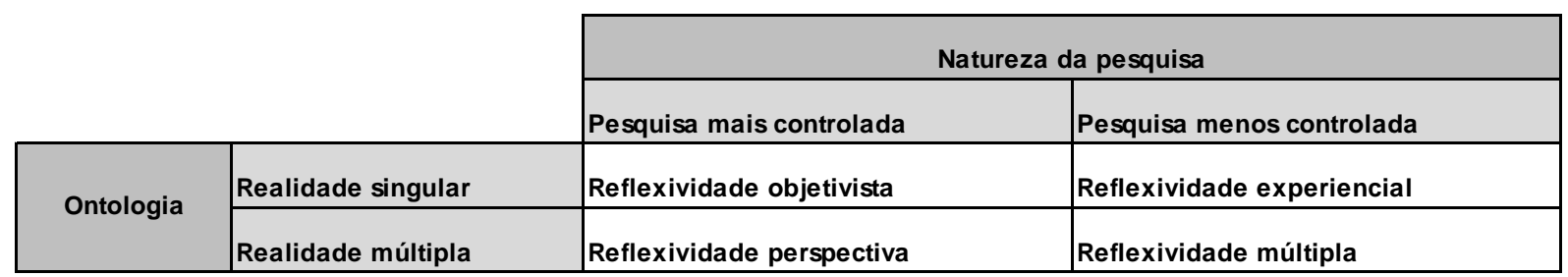

Fonte: Bettany e Burton (2006).

Figura 1. Natureza da pesquisa

Bettany e Burton (2006) defendem que não há qualquer argumento que faça uma reflexividade possuir algum status de superioridade em relação a outra. A importância, neste caso, reside na compreensão do contexto em que determinada pesquisa irá atuar. Berger e Luckmann (2005) apontam que a dialética proporciona identificação com os outros e a autoidentificação, realizadas em um espaço de mundo social específico. Neste espaço, decorre o conhecimento de si, do outro e de seus contextos sociais.

Hirschman (1993) defende uma abordagem mais reflexiva da pesquisa ao incentivar o reconhecimento de pesquisadores e pesquisados como seres sencientes iguais, em detrimento de qualquer método ou prática que tenha como premissa a desigualdade de poder entre eles. Fischer e Bristor (1993) seguem por mesmo caminho ao encorajarem uma abordagem mais colaborativa, aberta e sensível da pesquisa.

Hirschman e Holbrook (1986) afirmam que uma compreensão humanista de uma pesquisa só é possível por meio da interação pessoal e direta do pesquisador, que funciona como instrumento de medição de uma verdade que não se revelará como objetiva. Ao proporem este debate de maneira não definitiva, Bettany e Burton (2006) encorajam a construção de um diálogo sobre a tratativa de pesquisas em TCR e seus objetos.

Ainda que a literatura não sobreponha a pesquisa qualitativa sob a quantitativa, a TCR reconhece que a pesquisa de cunho qualitativo oferece maior possibilidade de sucesso no que tange ao seu aspecto transformador (Mertens, 2012), visto que a inclusão de uma dimensão qualitativa em pressupostos metodológicos é essencial para o estabelecimento de um diálogo entre pesquisadores e os pesquisados (Mertens, 2009), facilitando a prática sensibilizante e de incentivo à discussão, parte de uma ação transformadora (Ozanne et al., 2016). A escuta que concede espaço e voz aos oprimidos, que em TCR são chamados de vulneráveis (Tadajewski et al., 2014), perpassa pela compreensão do indivíduo e seu entorno social, considerando também o elemento histórico.

A ciência busca a resolver problemas em um contexto metodológico denominado paradigma, que determina um padrão de trabalho para um conjunto de pesquisadores (Kuhn, 1962). Este trabalho propõe que o uso de múltiplos paradigmas permite explorar melhor a relação entre o desenvolvimento e a prática do 
consumidor em maior profundidade (Bradshaw-CamBall \& Murray, 1991), uma compreensão essencial para a promoção da justiça social, ao contrário do que é possível com o uso do paradigma único (Lewis \& Grimes, 1999; Lewis \& Kelemen, 2002). As abordagens multiparadigmáticas, ao adotarem múltiplas lentes teóricas, apoiam a análise de fenômenos especialmente complexos e até contraditórios (Lewis \& Grimes, 1999).

Burrell e Morgan (1979) aclaram o sentido de paradigma como ideologias, ontologias, epistemologias e metodologias fortemente combinadas, resultando em modos de análise. A tipologia dos autores apresenta quatro paradigmas identificados pela asserção sobre a essência das ciências sociais e da sociedade, o funcionalismo, $\quad 0$ estruturalismo, $\quad 0$ interpretativismo e o humanismo radical, navegando em concepções mais ou menos objetivistas.

0 paradigma funcionalista se orienta pela sociologia da regulação e aborda seus sujeitos de uma perspectiva objetivista, procurando conceder explicações essencialmente racionais das relações sociais. Sua preocupação consiste na compreensão da sociedade para que o conhecimento gerado possa ser colocado em uso. Guiado pelo positivismo sociológico, lança mão de modelos e métodos usados e inspirados nas ciências naturais para estudar as relações humanas.

0 paradigma interpretativo busca o entendimento do mundo social por meio da experiência subjetiva. Trata-se de uma abordagem nominalista, anti-positivista, voluntarista e ideográfica. 0 paradigma humanista radical importa-se com o desenvolvimento de uma sociologia da mudança radical por meio da subjetividade. Busca sobrepujar as limitações das configurações sociais. 0 paradigma estruturalista radical propaga a sociologia da mudança radical a partir da objetividade, concentrando-se nas relações estruturais em um contexto social real.

Assim, as ciências sociais podem ser assimiladas sobre o prisma da objetividade ou subjetividade e a sociedade entendida sobre o manto da regulação ou mudança radical (Lewis \& Grimes, 1999), sendo esses os elementos que atuam na diferenciação dos paradigmas. A objetividade compreende que a realidade externa pode ser mensurada, determinada, prevista e generalizada.

A pesquisa empírica que se utiliza do pressuposto objetivista busca as relações entre os elementos, utiliza técnicas estatísticas, hipóteses, previsão, mensurabilidade, generalização e apresenta a condução da pesquisa por meio de procedimentos previamente definidos e estruturados (Vergara \& Caldas, 2005).

A subjetividade tem como premissa básica o estado mutável da sociedade e do indivíduo por meio de contextos e construções sociais que não podem ser generalizados para toda uma população. A regulação entende que as relações sociais são determinadas, harmônicas e ordenadas, ao passo que a mudança radical compreende que os conflitos, o poder e a agência são elementos que influenciam e transmutam diretamente o ambiente (Burrel \& Morgan, 1979; Lewis \& Grimes, 1999).

0 pressuposto subjetivista busca compreender a relação entre o indivíduo e o meio, utiliza-se de procedimentos pouco estruturados, amostras intencionais, não busca a generalização e a análise é realizada por vias interpretativas (Vergara \& Caldas, 2005).

Ainda que a TCR permita o uso indistinto de paradigmas, este trabalho defende que uma pesquisa transformadora em prol da justiça social alçará maior sucesso se lançar mão de um uso combinado de paradigmas em um mesmo estudo ou até mesmo proporcionar a criação de novas abordagens, seguindo o pensamento Paes-de-Paula (2016).

Paes-de-Paula (2016) defende que o conhecimento se desenvolve por meio de revoluções científicas, sugerindo um abandono da lógica explicativa kuhniana como tentativa de se alcançar outro patamar de conhecimento, dando como ilimitada a quantidade de sistemas de conhecimento que podem ser desenvolvidos. Para tal, a autora se utiliza do pensamento de Hill (1984) ao apontar os aspectos necessários para a construção de um sistema de produção de conhecimento, que deveriam conter os seguintes argumentos: as diferentes perspectivas filosóficas, metodológicas e teóricas nas ciências sociais são sistemas de produção de conhecimento; não há limite para o número de sistemas de produção de conhecimento que podem ser inventados ou propostos. 
Cada sistema de produção de conhecimento é composto pelos seguintes elementos: (1) visões de mundo metacientíficas, (2) metodologias e (3) teorias; esses elementos de cada sistema de produção de conhecimento são interdependentes; cada sistema de produção de conhecimento tenta manter a consistência entre seus elementos de acordo comas próprias regras de organização e lógica; cada sistema de produção de conhecimento é epistemologicamente responsável pelas suas próprias regras de organização e lógica.

A fidelidade da responsabilidade epistemológica para com o sistema de produção de conhecimento requer: (1) a completa articulação dos elementos de seu sistema; (2) a proposição de soluções para inconsistências quando elas são descobertas, e (3) a clara identificação e publicização de quaisquer inconsistências que resistam às soluções propostas; a investigação epistemológica frequentemente requer a escavação e reconstrução de elementos perdidos do sistema de produção de conhecimento. A partir dele, teorias e metodologias são desenvolvidas, orientando do ponto de vista epistêmico as abordagens sociológicas.

As abordagens sociológicas dos paradigmas geram teorias e metodologias que se orientam de acordo com três matrizes epistêmicas, inspiradas em uma filosofia e lógica de pensamentos singulares, conforme os três interesses cognitivos levantados por Habermas (1968/1982): a matriz empírico-analítica (interesse técnico), a matriz hermenêutica (interesse prático) e a matriz crítica (interesse emancipatório). Na matriz empírico-analíticas estão as ciências orientadas pelo interesse técnico, ou seja, no conhecimento gerado para possibilitar a previsão e o controle dos fatos sociais. A matriz hermenêutica concentra as ciências direcionadas pelo interesse prático, são aquelas que almejam o entendimento social por meio da interpretação e comunicação. A matriz crítica que se move pelo empenho emancipatório, preocupando-se com a transformação social. Tais matrizes devem ser utilizadas como orientadoras do conhecimento e não como domínio de atuação científica ou como concorrentes, mas sim como complementares, haja vista que o exercício da vida social necessita de todas elas.
Para Paes-de-Paula (2016), as abordagens funcionalista (matriz empírico-analítica), interpretativista (matriz hermenêutica) e humanista (matriz crítica) podem ser consideradas puras, ainda que os pesquisadores que nelas atuam possam produzir teorias e metodologias fronteiriças, sem fundar uma nova abordagem sociológica. Em alguns casos, a ruptura pode ocorrer, criando uma abordagem cruzada, capaz de sustentar conexões entre as matrizes epistêmicas. As abordagens estruturalista (matriz empírico-analítica e matriz hermenêutica), pós-estruturalista (matriz hermenêutica e matriz crítica) e realista crítica (matriz empírico-analítica, matriz hermenêutica e matriz crítica) se configuram como híbridas, conforme pode ser representado na figura 2.

Haja vista os três interesses cognitivos discutidos por Habermas (1968/1982) estarem em sintonia com as quatro diretrizes de atuação da TCR, que são: 1) sabedoria prática; 2) contribuição teórica; 3) mudança social; e 4) estratégia alternativa de comunicação, este trabalho defende que o uso da abordagem realista crítica é a mais relevante para estudos em TCR que se utilizem da justiça social como inspiração, uma vez que incentiva a utilização de elementos oriundos de todas as outras abordagens.

Esta defesa está de acordo com o pensamento de Paes-de-Paula (2016), que afirma que é preciso admitir a impossibilidade de dispor de toda a verdade baseando-se em determinado paradigma ou abordagem sociológica, fazendo com que o diálogo se torne fundamental.

A abordagem realista crítica é produto de um novo desenvolvimento epistêmico avançado, aberto e tolerante (Paes-de-Paula, 2016), fundamentado no real. Trata-se de uma abordagem defensora de um mundo edificado não apenas por eventos (empirismo) ou formações mentais (idealismo), mas por estruturas que se mantem atuantes independentemente do conhecimento, experiência ou meios de acesso a elas (Prado, 2009), o que se assemelha a percepção da injustiça social, apresentada no início deste trabalho.

Em face a toda essa discussão sobre justiça social e TCR, torna-se adequado conduzir a 
discussão sobre as possíveis conexões entre esses tópicos, assunto da próxima seção.

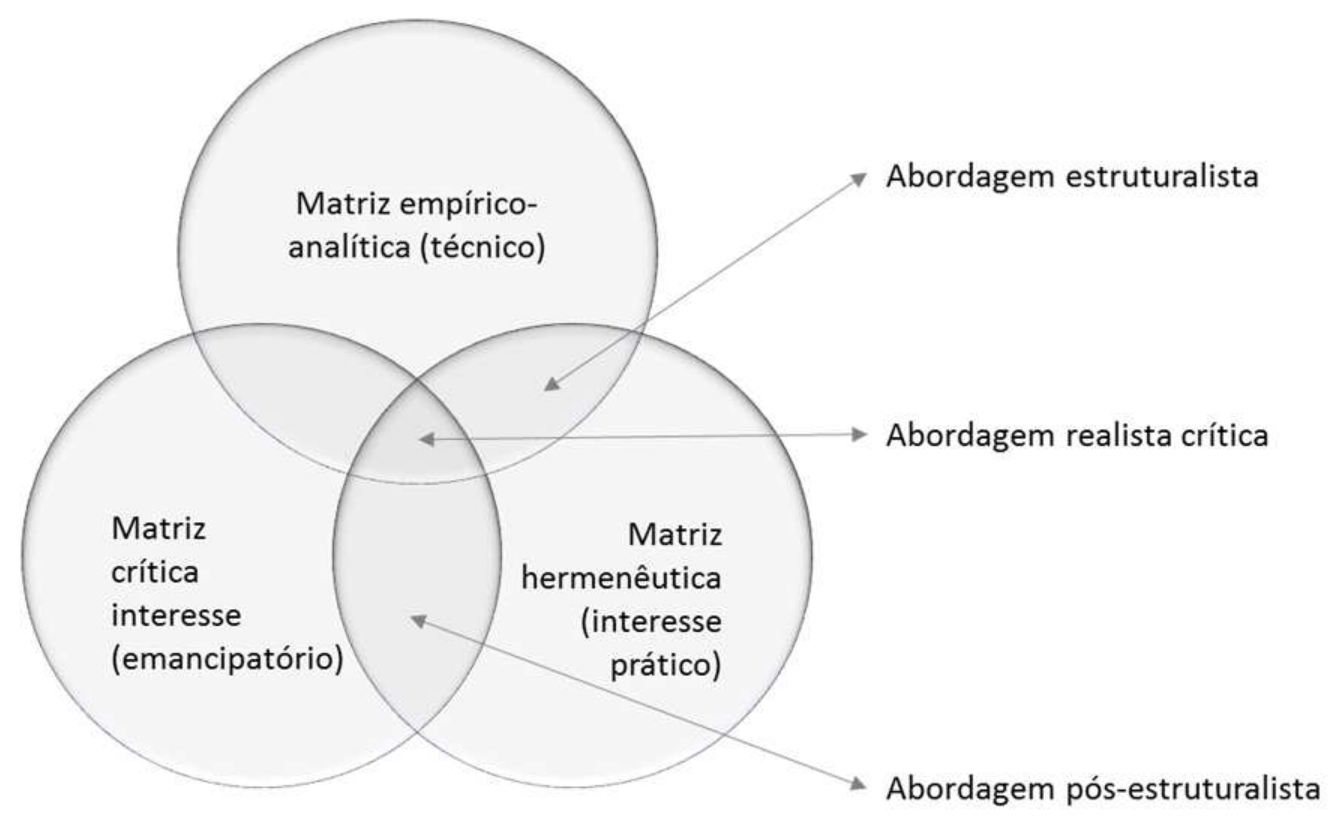

Fonte: Fonte: Paes-de-Paula (2016)

Figura 2. Círculo das Matrizes Epistêmicas

\section{CONECTANDO AS PARTES: A TCR E A JUSTIÇA SOCIAL}

Como apresentado na primeira parte deste ensaio, justiça social é um conceito complexo que se utiliza de temas sensíveis para formar seu significado. Em seu capítulo intitulado de "Dos Princípios Gerais da Atividade Econômica", inserido no título VII, "Da Ordem Econômica e Financeira", a Constituição Federal do Brasil (1988), em seu artigo 170, esclarece que justiça social se fundamenta na soberania nacional; propriedade privada; função social da propriedade; livre concorrência; defesa do consumidor; defesa do meio ambiente; redução das desigualdades regionais e sociais;busca do pleno emprego; e tratamento favorecido para as empresas de pequeno porte constituídas sob as leis brasileiras e que tenham sua sede e administração no país.

Dessa forma, o princípio da justiça social, que é atrelado ao bem-estar no artigo 193 do mesmo documento, visa a redução dos desequilíbrios sociais por meio da promoção da igualdade no que se refere a liberdade, dignidade e oportunidades.

A definição de bem-estar, elemento central na TCR, merece a mesma preocupação que perpassa pela compreensão de justiça social, estando estes conceitos muitas vezes ligados às percepções culturais. Bem-estar é um conceito difícil de ser generalizado, pois sua concepção perpassa por aspectos objetivos e subjetivos. Satisfação com a vida, qualidade de vida percebida e felicidade formam exemplos de elementos da assimilação subjetiva de bemestar. Indicadores econômicos, sociais e ambientais, por exemplo, compõem o entendimento objetivo (McGregor \& Goldsmith, 1998).

Ao optar pelo bem-estar do consumidor como o tema dominante e direcionador de suas pesquisas, a TCR assume a importância do equilíbrio entre as necessidades físicas, psicológicas, econômicas e sociais das pessoas nos ambientes de consumo, ao mesmo tempo em que contribui para a valorização da igualdade, justiça social e a distribuição 
igualitária de recursos e oportunidades, encaixando-se, sem maiores problemas, na ideologia de justiça social.Além disto, o exame de questões sociais no contexto em que ocorrem, ocasionado pelo incentivo à pesquisaação, permite e incentiva uma análise sociocultural complexa e mais ampla (Mick, 2006). Em suma, a TCR se assenta no mesmo pressuposto da justiça social, a existência da desigualdade e a necessidade de atenuá-la.

Ao se misturar ao arcabouço crítico, a TCR entende que os efeitos negativos do marketing se concentram por detrás de uma retórica corporativa, tomando para si a tarefa de influenciar as pessoas tendo em vista sua eventual emancipação ou incentivo à busca de alternativas (Tadajewski et al., 2014), ou seja, transformação. Se a TCR pode realizar mudanças sociais que afetem a vida das pessoas (Tadajewski \& Hamilton, 2014), ela precisa se preocupar em conhecer os problemas em níveis mais profundos de abstração (Mick et al., 2012), se envolvendo com as partes interessadas para obter um efeito social maior (Ozzane, 2017).

Esta tratativa exige a escolha de uma boa opção metodológica e adequada base teórica.Ao incentivar a busca pela compreensão, análise e transformação do bem-estar subjetivo e objetivo (McGregor \& Goldsmith, 1998), a TCR apenas reforça e impulsiona estudos ancorados na abordagem realista crítica.

Vale ressaltar que o interesse emancipatório isolado é crítica vazia, haja vista que os interesses práticos e técnicos são necessários para concretizar ações (Paes-de-Paula, 2016) e promover transformações. Somente com a junção dos três interesses é que a pesquisa atingirá a capacidade de interferir na realidade da maneira pela qual a TCR espera atingir em seus estudos.

Dessa forma, os estudos em TCR podem lançar mão, a partir de dados empíricos e de uma reflexividade múltipla, de uma abordagem hermenêutica que promova 0 interesse emancipatório fundamentado na percepção de injustiça social, especialmente aquela advinda das relações de consumo, resultando em um formato de intervenção adequado, amplo e condizente com as realidades objetivas e subjetivas.

Trazendo a discussão para o âmbito dos aspectos que foram apontados anteriormente como necessários para a agenda de pesquisas baseadas na promoção da justiça social (subsistência, saúde, segurança, sociabilidade, soberania e espiritualidade) há alguns comentários que são fundamentais. Todos eles parecem guardar uma expressiva aderência aos campos de atuação de estudos envolvendo a TCR.

Não se pode deixar de mencionar que além desses aspectos aderentes, as considerações acerca dos três componentes que perpassam todos eles também guardam pontos de contato com a TCR. Isso fica bastante óbvio quando se considera que a TCR se ampara em um "respeito" ao público entrevistado, visto que os problemas de pesquisa são "construídos" ao longo do processo de investigação, sempre na perspectiva dos sujeitos.

A TCR também parece ter aderência à questão de avaliar as tentativas inovadoras da promoção da justiça social, mesmo em uma escala relativamente limitada. Por fim, está no cerne das características da TCR a preocupação constante de se utilizar métodos, técnicas e teorias advindas de campos do conhecimento distintos no dia a dia do trabalho de campo.

Levando em conta os dois paradigmas relacionados à justiça social discutidos nas seções anteriores, também cabem alguns comentários. Percebe-se que ambos os paradigmas (o da redistribuição e 0 do reconhecimento) têm estreita aderência aos preceitos da TCR, embora seja interessante constatar que o público-alvo das pesquisas transformativas do consumidor são grupos marginais que, via de regra, apresentam algum tipo de relação com questões envolvendo gênero, sexualidade, nacionalidade e raça.

\section{CONSIDERAÇÕES TRANSITÓRIAS}

Ao chegar a esse ponto do ensaio, nomeamos a seção final como considerações transitórias por acreditarmos que não seria adequado fechar essas discussões como finais, muito menos como notas conclusivas. Como já enfatizamos no início do texto, a intenção foi de promover um "pontapé inicial" para uma discussão que pode (e deve) ser aprofundada em outros textos por outros autores com diferentes perspectivas. Contudo, percebemos que tal como apresentado na seção anterior, podemos afirmar que existem pontos de contato que possibilitam a estabelecimento de 
articulações entre os estudos sob a perspectiva da TCR e aqueles trabalhos que buscam promover a justiça social, a despeito da complexidade e das controvérsias envolvendo esse debate.

Resgatando as indagações que motivaram a elaboração do ensaio, conjuntamente com a proposição do objetivo do texto, podemos afirmar que as questões foram respondidas e nosso intento foi atingido. Além disso, voltando à indagação presente no título do trabalho, também podemos afirmar que a busca por justiça social nos estudos na perspectiva da TCR é algo plausível e desejável com ganhos para ambos os lados.

No mesmo sentido, não se pode deixar de mencionar que é sempre salutar todo esforço de promover "pontes" entre diferentes campos do conhecimento, ponto em que o realismo crítico é ainda mais recomendado. No mundo social em que a TCR se propõe a atuar, papéis e identidades de pessoas e instituições estão inter-relacionados, isso significa que os sistemas sociais envolvem "dependências ou combinações que afetam causalmente os elementos ou aspectos, e a forma e estrutura dos elementos seinfluenciam causalmente e, portanto, também o todo" (Lawson, 1997: 64).

Assim, os diferentes tipos de interseções que formam um problema precisam ser investigados em TCR para que o resultado de seu estudo seja realmente impactante e contribua, de fato, para uma discussão que promova a minimização da injustiça social. A pesquisa em TCR deve servir a um projeto de transformação social com foco no fortalecimento do consumidor, para tanto, na elaboração de seus trabalhos, é preciso levar em contatos aspectos históricos, os atores envolvidos e suas características, o contexto em esfera ampla e reduzida, a condição de reprodução do problema e dos dados produzidos, até mesmo o perfil dos pesquisadores.

De qualquer forma, apesar de termos pinçados aspectos essenciais envolvendo a justiça social e a TCR, ainda sobram pontos que não tivemos condições de aprofundar e que, por isso, podem servir de ponto de partida para estudos futuros. Para aqueles pesquisadores que se sentiram atraídos pela temática, vale apontar algumas sugestões para futuros debates.
Em primeiro lugar, deve-se considerar que seria interessante a ampliação de discussões envolvendo tanto o Estado como a sociedade civil organizada como atores essenciais no processo de promoção de justiça social que também podem fazer parte dos estudos transformativos do consumidor. Esse, aliás, é um ponto que, por ser pouco explorado na literatura de TCR, pode ser trabalhado de forma contundente em futuros trabalhos teóricos da temática.

Em segundo lugar, tal como também apontado por Pizzio (2016), a percepção dos gestores de políticas públicas sobre a importância das ações compartilhadas amparadas pela paridade participativa e pelo reconhecimento social são de especial relevo para se articular justiça social e TCR. Ganha relevo, nesse contexto, no contorno do que foi discutido sobre a ontologia e a natureza das pesquisas transformativas nas seções anteriores, a necessidade de incorporação de metodologias e técnicas de coleta e análise de dados mais participativas, ainda consideradas como pouco usuais no campo do consumo. A apresentação, discussões e formas de implementação desses métodos e técnicas podem ser sinalizadas como interessantes para o campo.

Em terceiro lugar, a TCR, apesar de todo seu desenvolvimento nos últimos anos, ainda precisa se cercar de uma base teórica mais pujante e aprofundada. A conjugação com toda a discussão de justiça social atrelada às diversas temáticas englobando desenvolvimento sustentável, condição de grupos marginais, excluídos ou "invisíveis" e sua inclusão social, além de outras temáticas que ainda estão por emergir podem ser salutares para arejar e manter vivo o campo da TCR como perspectiva interessante no campo dos estudos do consumo. Aliás, é essa a grande proposta da TCR: uma modalidade ou "estilo" de pesquisa mais engajada social e que possa resultar na melhoria de sua qualidade de vida e da própria sociedade.

Não é escusado afirmar que embora essa articulação possa fazer sentido em nível teórico, é essencial ir para o campo, colocar em prática toda essa discussão e, essencialmente, se "intrometer" nos problemas vivenciados pelos pesquisados para tornar toda essa discussão com sentido para os estudos do consumo e para a sociedade como um todo. 
Em suma, acreditamos que o ensaio cumpriu seu papel que foi o de convidar os pesquisadores do consumo a irem além das "estruturas" formais do campo, trazendo para o debate outras trilhas (cheia de dificuldades, mas também de surpresas) que podem contribuir para o campo com pesquisas que possam fazer sentido para todos os envolvidos e, principalmente, fazer diferença para a sociedade.

\section{REFERÊNCIAS}

ACR. Association for Consumer Research. Transformative Consumer Research. 2017. Disponível em <http://www.acrwebsite.org/web/tcr/transf ormative-consumer-research.aspx $>$. Acesso em: 30 mai. 2017.

Almeida, T. G. \& Casotti, L. M. (2015). Turismo voluntário e o bem-estar do consumidor na pesquisa transformativa do consumo. Revista Ciências Administração, 21(2), 531-553.

Andrade, J., Hamza, K. M., \& Xara-brasil, D. M. (2017). Business ethics: International analysis of codes of ethics and conduct. Revista Brasileira de Marketing, 16(1), 1-15.

Berger, P. L.; \& Luckmann, T. (2005). A construção social da Realidade: Tratado de Sociologia do Conhecimento. 25 ed. Petrópolis: Vozes.

Bettany, S.; \& Burton, L. (2006). Steps towards transformative consumer research practice: A taxonomy of possible reflexivities. Advances in Consumer Research, 33, 227-234.

Bradshaw-Camball, P., \& Murray, V. V. (1991). Illusions and other games: A trifocal view oforganizational politics. Organization Science, 2(4), 379-398.

Bristor, J. M.; \& Fischer, E. (1993). Feminist thought: Implications for consumer research, Journal of Consumer Research, 19, 518-536.

Burrell, G.; \& Morgan, G. (1979). Sociological paradigms and organisational analysis: Elements of the sociology of corporate life. Vermont: Ashgate.

Coelho, P. F. C. (2015). A pesquisa transformativa do consumidor: Reflexões e diretrizes para pesquisadores brasileiros. Revista Economia \& Gestão, 15(40), 4-27.

Cohen, G.A. (2004). The market: On the site of distributive justice. In Social justice, Clayton, M.\& Williams, A., eds. London: Blackwell.

Correa, R. S., Pinto, M. R., \& Batinga, G. L. (2016). A beleza na escuridão: um "olhar" sobre a experiência de consumo por mulheres deficientes visuais em serviços de beleza e estética. Revista Ciências Administrativas, 22(2), 371-395.

Damascena, E. O. (2013). Elementos sensoriais em supermercados: Uma investigação na perspectiva transformativa do consumidor junto a pessoas com deficiência visual. Dissertação (Mestrado em Administração) Universidade Federal de Pernambuco, Recife, PE.

Faria, M. D. \& Motta, P. C. (2012). Pessoas com deficiência visual: Barreiras para o lazer turístico. Revista Turismo em Análise, 23(3), 691-717.

Faria, M. D. \& Silva, J. F. (2011). Composto para restaurantes: Atendendo consumidores com deficiência visual. Revista de Administração FACES Journal, 10(1), 11-32.

Faria, M. D. \& Casotti, L. M. (2014). Representações e estereótipos das pessoas com deficiência como consumidoras: 0 drama dos personagens com deficiência em telenovelas brasileiras. Revista Organização \& Sociedade, 21(70), 387-404.

Fraser, N. (2001). Da redistribuição ao reconhecimento? Dilemas da justiça na era pós-socialista. In J. Souza (org.) Democracia Hoje: novos desafios para a teoria democrática contemporânea (pp. 245-282). Brasília: EditoraUnB.

Gough, I. (2017). Recomposing consumption: Defining necessities for sustainable and equitable well-being. Philosophical Transactions of The Royal Society A Mathematical Physical and Engineering Sciences, 375(2095), 1-18.

Habermas, J. (1967). A lógica das ciências sociais. Petrópolis: Vozes.

Hamilton, K.; et al. (2014). Poverty in consumer culture: Towards atransformative social representation. Journal of Marketing Management, 30(17-18), 1833-1857.

Hein, W.; et al. (2016). Gender justice and the market: A transformative consumer research perspective. Journal of Public Policy \& Marketing, 35(2), 223-236.

Hill, M. R. (1984). Epistemology, axiology, and ideology in sociology. Mid-American Review of Sociology, 9(2), 59-77.

Hirschman, E. C.; \& Holbrook, M. B. Expanding the ontology and the methodology of research on the consumption experience. In: BRINBERG, D.; LUTZ, R. J., Perspectives on methodology in consumer research. New York: Springer Verlag, 1986.

Hirschman, E.C. (1993). Ideology in consumer research, 1980 and 1990: A marxist and 
feminist critique. Journal of Consumer Research, 19, 537-555.

Janczura, R; (2012). Risco ou vulnerabilidade social? Textos \& Contextos, 11, 301-308.

Johnson, G. D.; Thomas, K. D.; \& Grier, S. A. (2017). When the burger becomes halal: a critical discourse analysis of privilege and market place inclusion. Consumption Markets \& Culture, 1-26.

Kuhn, T. (1962). A estrutura das revoluções científicas. 5. ed. São Paulo: Perspectiva.

Lewis, M. W.; \& Kelemen, M. L. (2002). Multiparadigm inquiry: Exploring organizational pluralism and paradox. Human Relations, 55(2), 251-275.

Lewis, M. W.; Grimes, A. J. (1999). Metatriangulation: Building theoryfrom multiple paradigms. Academy of Management Review, 24(4), 672690.

Loureiro, Y. L.; et al. (2016). The case for moral consumption: examining and expanding the domain of moral behavior to promote individual and collective well-being. Journal of Public Policy \& Marketing, 35(2), 305-322.

Mari, C. (2008). Doctoral education and transformative consumer research. Journal of Marketing Education, 30(1), 5-11.

Mcgregor, S., \& Goldsmith, E. (1998). Expanding our understanding of quality of life, standard of living, and well-being. Journal of Family and Consumer Sciences, 90(2), 2-6.

Mertens, D. M. (2009). Transformative research and evaluation. New York, NY: Guilford.

Mertens, D. N. (2012). Transformative mixed methods: Addressing inequities. American Behavioral Scientist, 56(6), 802-813.

Mick, D. G. (2006). Meaning and mattering through transformative consumer research, In Pechmann C. \& Price L. L. (Eds.), Advances in Consumer Research. Provo, UT: Association for ConsumerResearch.

Mick, D. G.; Pettigrew, C.; Pechmann, J.; L. Ozanne (eds.), Transformative consumer research for personal and collective well-being. New York: Routledge, 2012.

Miller, D. (1999). Principles of social justice. Cambridge, MA: Harvard University Press.

Okin, S. M. (1991). Justice, gender, and the family. New York: Basic Books.

Oliveira, L. D. S., \& Lima-filho, D. O. (2011). Modelo de segurança alimentar e nutricional e seus determinantes socioeconômicos e comportamentais. Cadernos Gestão Pública e Cidadania, 16(59), 1-20

Ozanne, J.; et al. (2011). The practice of transformative consumer research: some issues and suggestions. Journal of Research for Consumer, 19.
Ozanne, J.; et al. (2017). Assessing the societal impact of research: the relational engagement approach. Journal of Public Policy \& Marketing, 36(1), 1-14.

Paes-de-Paula, A. P. (2016). Para além dos paradigmas nos estudos organizacionais: 0 círculo das matrizes epistêmicas. Cadernos EBAPE.BR, 14(1), 24-46.

Peña, C. R., Pinheiro, D. S., Albuquerque, P., \& Fernandes, L. M. (2015). A eficácia das transferências de renda: as tendências da desigualdade antes e depois do Programa Bolsa Família. Revista de Administração Pública, 49(4), 889-913.

Pinto, M. R., Batinga, G. L., Assimos, B. M. \& Almeida, G. T. (2016). Transformative consumer research (TCR): Reflexões, diretrizes e uma análise do campo no Brasil. RIMAR - Revista Interdisciplinar de Marketing, 6(2), 54-66.

Pizzio, A. (2016). Embates acerca da ideia de justiça social em relação a conflitos sociais e desigualdades. Revista de Administração Pública, 50(3), 355-375.

Pogge, T. W. (2004). Justice across borders: Brief for a global resources dividend. In Social Justice, Clayton, M. \& Williams, A., eds. London: Blackwell.

Prado, E. F. S. (2009). Economia, complexidade $e$ dialética. São Paulo: Plêiade.

Scott, L; et al. (2011). Beyond poverty: Social justice in a global marketplace. Journal of Public Policy \& Marketing, 30(1), 39-46.

Sridharan, S.; Barrington, D. J.; \& Saunders, S. G. (2017). Markets and marketing research on poverty and its alleviation: summarizing anevolving logic toward human capabilities, well-being goals and transformation. Marketing Theory, 17(3), 1-18.

Silveira, R. Z. (2013). Mãe!? O mundo vai acabar...? Reflexões sobre desdobramentos e implicações dos paradigmas sociológicos de Burrell e Morgan para os estudos organizacionais. Cadernos EBAPE.BR, 11(4), 652-670.

Sirgy, M. J., Lee, D. \& Rahtz, D. (2007). Research on Consumer Well-being (CWB): overview of the field and introduction to the special issue. Journal of Macromarketing, 27(4), 341-49.

Tadajewski, M.; et al. The discourses of marketing and development: Towards 'critical transformative marketing research'. Journal of Marketing Management, 30(17-18), 17281771.

Vasconcelos, I. F. F. G., \&Irigaray, H. A. R. (2017). Editorial: Pesquisa científica em administração e justiça social. Cadernos EBAPE.BR, 15(2), 1-2. 
Vergara, S.; \& Caldas, M. (2005). Paradigma interpretativista: A busca da superação do objetivismo funcionalista nos anos 1980 e
1990. Revista de Administração de Empresas, 45(4), 66-72.

\title{
Social Justice and Transformative Consumer Research: The proposition of a theoretical reflection
}

\begin{abstract}
When something is classified as socially unfair, it means that someone has less than they should have.The purpose of this paper is to instigate an initial reflection about the possibilities of linking the social justice discussion with studies based on the Transformative Consumer Research (TCR), taking in consideration the primary intention to bring to the studies of public consumption and research questions which are historically marginalized, seeking to promote the welfare through some kind of social change. It is necessary that different types of intersections that form a problem are investigated for what, indeed, a deep discussion to minimize social injustice. Thus, this paper argues that the TCR can help in the promotion of social justice in view of the opportunities it offers in increasing discussions involving the public management and civil society, especially with the use of a realistic critical research approach.
\end{abstract}

Keywords: Transformative Consumer Research, Social Justice, Critical Realism. 